\title{
The performance implications of contextual marketing for electronic commerce
}

Received (in revised form): 6th February, 2003

\section{Xueming Luo}

is an Assistant Professor of Marketing in the School of Business, State University of New York at Fredonia. His research interests include strategic marketing, e-business strategies, knowledge management, and international marketing business. He has published articles in the Journal of Business Research, the International Journal of Research in Marketing and other publications of repute.

Abstract Consumers may access the interweb and internet anywhere anytime via wireless devices. The strategy of contextual marketing (CM), or providing customised and contextual information to customers at the point of need in real time, becomes the key to reaching and retaining online customers. This study attempts to empirically explore the new business model of $\mathrm{CM}$ and its resulting e-commerce performance in a business-to-consumer setting. Survey data of online users were utilised to examine quantitatively the perceived importance of $\mathrm{CM}$ and both its potential positive and negative outcomes. The results provide some initial evidence of its positive influence on users' perceived e-commerce outcomes (eg, site value, user satisfaction and online purchases). In addition, the results indicate that $\mathrm{CM}$ does not necessarily lead to a higher level of negative outcomes (eg, consumer complaint behaviours of providing incomplete information and incorrect information online), although one may expect them as the potential dark side of technology development.

\section{INTRODUCTION}

Information technology (IT) advances are reshaping business models and marketing practices in most industries. New technologies (wireless web, personal digital assistants or PDAs, interactive television, etc) create ample opportunities to effectively target customers in real time in the virtual space. In the next five years, a large number of internet users will access the web and shop online through wireless devices such as web-enabled cellphones, laptops and PDAs. In Asian countries, as high as 34.8 per cent of the 115 million internet users go online wirelessly already, representing a wireless market with enormous marketing and business opportunities. This colossal wireless cybermarket will soon become the truth in the USA. ${ }^{1}$ Yet, few direct marketing practitioners are capitalising on the surge of these wireless web users. Skygo and Versign are applying a direct-response platform that allows mobile telephone users and advertisers to interact and respond to each other in real time. In Japan, wireless carrier NTT DoCoMo's I-mode service offers its more than 10 million consumers wireless access to hotel reservations, restaurant locators, ski resorts, real-time stock prices and the like. The I-mode service is very successful and profitable by providing relevant and contextual information when online users want it at the point of need in real time, not just when they sit in front of PCs. This strategy of providing personalised 
information to customers at the point of need in real time is termed the new business model of contextual marketing $(\mathrm{CM}) .^{2}$

Although the theoretical importance of $\mathrm{CM}$ has been introduced in the literature, knowledge of CM is still limited in the sense that there is no empirical investigation to test and potentially extend this theory. Yet, a theory-based test is much needed to manifest the relevance and applications of $\mathrm{CM}$ in practice. As a result, this study aims to extend the theory of CM into a new frontier by empirically exploring its influence on web users' perceived e-commerce outcomes in a business-to-consumer setting. It represents the first study to link consumers' perceived importance of CM with both positive e-commerce outcomes such as site value, user satisfaction and repeated purchase, and negative ones such as consumer complaint behaviours providing incomplete and/or incorrect information online. The rest of the paper will proceed first with a brief review of the CM concept and relevant theories in information systems and marketing, followed by a discussion of hypothesis development.

\section{LITERATURE REVIEW AND HYPOTHESIS DEVELOPMENT}

\section{The origin of contextual marketing (CM)}

The origin of CM begins with the marketspace theory of business by Rayport and Sviokla. ${ }^{3}$ These scholars argue that IT advances are transforming the marketplace view of business to marketspace one, in which a transaction may happen without a physical buyer and a physical seller. However, these two parties are required for the traditional marketplace-based transaction.
Importantly, this information systems theory holds that value can be created for customers in the electronic marketspace by three elements content, context and infrastructure. Content refers to what information firms offer to customers on the web. While infrastructure is what enables the exchange and the added value to occur and context refers to how firms offer information (or content) to customers. Based upon this marketspace perspective, traditional e-business models focusing on content offerings failed to generate profits. Most of the content of the destination website does not suit customer needs. What customers are demanding online are tailored, customised messages and information provided by contextual marketers at the point of purchase. For this reason, they predict that the key to successful e-commerce has shifted from content (the information itself) to context (the way to deliver the information).

Therefore, they call for urgent research of CM strategy. CM is posited to bring in repeated purchase and numerous competitive advantages (eg, loyal customers, cross-selling and up-selling opportunities) to e-businesses. Yet, no study has empirically tested such potential performance implications in the literature.

Marketers who take advantage of the ubiquitous internet and CM capabilities will gain substantial competitive advantages. First, they will have more efficient targets of marketing segments in that they may catch the eye of consumers by proactively providing needed, relevant products and services. In the industry, most traditional banner ads cost even 2.5 times more than those in the offline world; but a web-based banner ad may only have a click-through rate of 0.5 per cent or less. ${ }^{4}$

Furthermore, today's society highly values 
time. Customers may be willing to pay a premium price for relevant products at the point of need in exchange for saved information-searching time. For example, when a traveller needs to change travel plans mid-journey, they may urgently need web-enabled mobile devices to book new flights, make new hotel reservations, and schedule ground transportation. It is not hard to imagine that such a traveller would be willing to pay a premium price to save search time and effort, in this accidental situation, to obtain the associated services and products.

\section{Potential positive influences of $\mathrm{CM}$}

From a buyer perspective, the adoption of CM may help internet users to perceive more value and usefulness from websites, to achieve a higher level of user satisfaction with the online experience, and to be more willing to purchase via the sites. Site value can be defined as the extent to which users perceive the sites to be useful, important and valuable. Customers may adopt the disruptive innovation of the internet mainly because it offers great benefits and superior value to them. Commonly believed benefits of the site include its convenience, ubiquity, low entry costs and lack of time or space limitations. If a user does not perceive the site to be valuable, satisfying or gratifying, he or she may never bother to experience the medium again. In the dynamic, turbulent electronic market, the value of information depreciates quickly and, thus, the time sensitivity should be high in the information age. As such, the capability of real-time communication of CM may become a key issue of strategic planning and a resource of competitive advantage for e-business in gaining customer loyalty and satisfaction. In addition, contextual and relevant messages will add more perceived site value to online consumers. CM expands ways to connect to customers whenever and wherever they are ready to purchase, leading to superior customer relationship management, loyalty, satisfactory online experience and repeated purchases online. Therefore, the following hypotheses are offered:

$$
\begin{aligned}
\mathrm{H}_{1}: & \text { Higher level of contextual } \\
& \text { marketing is associated with a } \\
& \text { higher level of perceived site } \\
& \text { value. } \\
\mathrm{H}_{2}: & \text { Higher level of contextual } \\
& \text { marketing is associated with a } \\
& \text { higher level of perceived user } \\
& \text { satisfaction. } \\
\mathrm{H}_{3}: & \text { Higher level of contextual } \\
& \text { marketing is associated with more } \\
& \text { online purchases. }
\end{aligned}
$$

\section{Potential negative influences of $\mathrm{CM}$}

With the positive influences of CM in mind, it must be acknowledged that CM strategy may be limited to some extent due to the generally high level of web users' privacy concern associated with technology adoption and utilisation. In other words, CM may also generate negative influences. One of these is online consumer complaint behaviour (CCB), such as providing incomplete or incorrect registration information or data. According to popular CCB taxonomy, it may have three different categories: voice, private and third party. Voice CCB responses are consumers' complaints directed to the sellers. While private responses are informal in the form of word of mouth, third party complaints are formal and, in theory, directed toward regulatory agencies. In the context of e-mail uses, Sheehan and Hoy $^{5}$ elaborate the associated online CCB. Their results show that online privacy concerns might induce voice, private and third party $\mathrm{CCB}$ such as 
providing incomplete or incorrect information online when web users received spamming electronic messages. Therefore, these types of CCB were examined in this research.

Consumer privacy refers to all personal information about one's body, behaviour, communication and other personal data. Concerns about privacy and security may lead most people not to shop online or leave the electronic marketspace. However, the successful implementation of the CM strategy of offering tailored and contextual information to individuals may need detailed and click-by-click customer information and transaction data. As consumers take control of and are highly concerned about information about themselves, privacy concerns may indeed impose a hurdle to CM implementation. It would be expected that CM technologies (smart banner ads, pop-up windows of personalised products etc) may further challenge how users perceive the security of their personal and financial information. As a result, it is likely for online shoppers to avoid risk associated with CM practices by providing incorrect and/or incomplete information to web businesses.

\section{$\mathrm{H}_{4}$ : Higher level of contextual} marketing is associated with the higher level of online consumer complaint behaviours of providing incomplete information.

$\mathrm{H}_{5}$ : Higher level of contextual marketing is associated with the higher level of online consumer complaint behaviours of providing incorrect information.

\section{METHODOLOGY}

\section{Sample}

As this research was confined to the business-to-consumer section of e-commerce, perceptual data of online consumers were collected. Web users were instructed to report their evaluation of each statement based upon their experience with internet storefront sites selling CDs, books, computers, hotel rooms and the like. Using the intercept survey method, data of internet users were collected in a northeastern state. Taking care to reduce the sampling error, several research interviewers were recruited and trained. Part of their training specified that subject participating should only include individuals familiar with the internet and the web and that they must have at least one year's online experience. Using such screening criteria for internet usage, researchers were able to exclude 37 subjects. Among the total of 239 interviews, 180 questionnaires were useful, with a valid response rate of 75.31 per cent $(180 / 239)$.

Some characteristics of the sample are summarised next. Among the 180 usable responses, about half ( 51 per cent) of the online shoppers were female. Age ranged from 19 to 53 years, and the mean was 23 years. The majority of the users $(80$ per cent) used local internet service providers to connect to the internet. On average, the online shoppers spend seven hours per week on the web with more than four years of online experience. In addition, all subjects reported some purchase experience and most reported having purchased at least two times online.

\section{Scales}

In developing the final questionnaire, existing scales were used whenever possible. All measurement scales (except the online purchases) are Likert-type with a seven-point format, anchoring at ' 1 ' strongly disagree and ' 7 ' strongly agree. All measures used in the study are 
Table 1: The measurement items and CFA results

\begin{tabular}{|c|c|c|c|c|}
\hline Measurements $^{\mathrm{a}}$ & $\begin{array}{l}\text { Standard } \\
\text { weights }\end{array}$ & Error & $t$ values & $\begin{array}{l}\text { Composite } \\
\text { reliability }\end{array}$ \\
\hline \multicolumn{4}{|l|}{ Contextual marketing } & \multirow{7}{*}{0.841} \\
\hline $\begin{array}{l}\text { It is important for sites to develop banner ads that pertain } \\
\text { to my personal interests and needs in the right context }\end{array}$ & $0.751^{\mathrm{b}}$ & & & \\
\hline Using wireless devices to shop online is important to me & 0.737 & 0.101 & 9.069 & \\
\hline $\begin{array}{l}\text { It is important for sites to develop features that } \\
\text { 'come to me' in real time }\end{array}$ & 0.758 & 0.093 & 9.296 & \\
\hline It is critical to use kiosks in malls to find shopping discounts & 0.594 & 0.091 & 7.352 & \\
\hline $\begin{array}{l}\text { It is important to use wireless telephones that connect } \\
\text { to the internet to shop online in any place }\end{array}$ & 0.679 & 0.109 & 8.393 & \\
\hline \multicolumn{4}{|l|}{ I feel it is critical to use e-wallets when checking out ${ }^{c}$} & \\
\hline \multicolumn{4}{|l|}{ Site Value } & \multirow[t]{4}{*}{0.943} \\
\hline Internet storefront sites are very valuable to me & $0.938^{\mathrm{b}}$ & & & \\
\hline Internet storefront sites are very useful to me & 0.957 & 0.040 & 25.362 & \\
\hline Internet storefront sites are very important to me & 0.845 & 0.056 & 17.634 & \\
\hline \multicolumn{4}{|l|}{ Site satisfaction } & \multirow[t]{6}{*}{0.932} \\
\hline $\begin{array}{l}\text { I feel satisfied with the convenience of internet } \\
\text { storefront sites }\end{array}$ & $0.765^{\mathrm{b}}$ & & & \\
\hline I am satisfied with information on internet storefront sites & 0.741 & 0.088 & 10.547 & \\
\hline I am satisfied with online products and services selection & 0.740 & 0.086 & 10.532 & \\
\hline $\begin{array}{l}\text { Overall, I am pleased with my experience of internet } \\
\text { storefront sites }\end{array}$ & 0.939 & 0.078 & 14.127 & \\
\hline $\begin{array}{l}\text { Overall, I am satisfied with my experience of internet } \\
\text { storefront sites }\end{array}$ & 0.947 & 0.081 & 14.259 & \\
\hline
\end{tabular}

presented in Table 1 . In addition, the results of a confirmatory factor analysis (CFA) are shown in Table 1.

CM was measured by a new scale in this study. The six-item scale assesses the web users' perception of the importance of using wireless telephones with web access, using kiosks in malls to find shopping discounts, developing banner ads that pertain to personal interests and needs, using e-wallets when checking out, using wireless devices to shop online, and developing features that 'come to me' in real time. This scale seems to achieve the required convergent and discriminant validity, according to the CFA results reported and discussed in the next section.

The scale of site value consists of three separate Likert-type items. In particular, this measurement assesses the extent to which the site is useful to them, important to them and valuable to them. User satisfaction is measured by a five-item, Likert-type scale. Two items assess the overall perception of consumers being satisfied and pleased with the online experience. The other three items assess the degree to which consumers are satisfied with the convenience of the web, information on the web and the products and services offered online. CB measurements were taken directly from the existing literature. One item requested users' agreement (strongly agree or strongly disagree) on the extent to which they provide inaccurate information when registering for and browsing websites. The other assessed the degree of providing incomplete information when registering 
Table 2: Correlations matrix and summary statistics

\begin{tabular}{lllllllll}
\hline & Mean & SD & $\mathbf{1}$ & $\mathbf{2}$ & $\mathbf{3}$ & $\mathbf{4}$ & $\mathbf{5}$ & $\mathbf{6}$ \\
\hline 1. Contextual marketing & 4.25 & 1.02 & 1.00 & & & & & \\
2. Site value & 5.61 & 1.44 & $0.34^{\star \star}$ & 1.00 & & & & \\
3. User satisfaction & 5.24 & 1.08 & $0.29^{\star \star}$ & $0.76^{\star \star}$ & 1.00 & & & \\
4. Online purchase & 3.33 & 4.29 & $0.30^{\star \star}$ & $0.38^{\star \star}$ & 0.16 & 1.00 & & \\
5. Providing incomplete information & 3.84 & 1.79 & 0.14 & $-0.27^{\star \star}$ & -0.16 & 0.10 & 1.00 & \\
6. Providing incorrect information & 4.00 & 1.85 & 0.07 & $-0.24^{\star \star}$ & $-0.22^{\star \star}$ & $-0.15^{\star}$ & $0.65^{\star \star}$ & 1.00 \\
\hline
\end{tabular}

${ }^{*} p<0.05$

${ }^{\star \star} p<0.01$

for and browsing websites. Finally, online purchasing was assessed through a continuous ratio scale which measured the number of purchases web users made via the web during the previous year.

\section{RESULTS}

\section{Scale reliability and validity results}

Before testing the hypotheses, the reliability and validity of the multiple-item scales (CM, site value and satisfaction) used in the study were tested. All measurement models were evaluated with multiple criteria: reliability, unidimensionality, face validity, convergent validity and discriminant validity. First, evidence of internal consistency of the constructs was found in this study. The composite reliability of the CM measure was 0.84 , above the suggested threshold level. As reported in Table 1, site value and users' satisfaction with the web also possessed sufficient reliability, as the alphas were 0.94 and 0.93, respectively.

Furthermore, CFAs were employed to test the measurement model with all constructs of CM, site value and web user satisfaction in this study. The CFA results provided support for the unidimensionality, convergent and discriminant validity of the three-factor measurement model after dropping one indicator of the CM construct. All items' loadings on their corresponding construct (standardised estimators ranging from 0.59 with a $t$ value of 7.35 to 0.96 with a $t$ value of 25.36) were significant at $p<0.05$ as shown in Table 1 , demonstrating adequate convergent validity. Since the modification indices and estimated residuals from the CFA analysis were not significant, unidimensionality was also achieved. In addition, the discriminant validity of the model was supported by checking the pairwise correlations (eg, significantly different from 1.0) in Table 2. Overall model goodness-of-fit indices also supported the validity of this overall measurement model $\left(\chi^{2}=182.23\right.$; degree of freedom $=62, p=0.000$; comparative fit index $(\mathrm{CFI})=0.952$; the goodness-of-fit $(\mathrm{GFI})=0.912$; adjusted goodness-of-fit $($ AGFI $)=0.905$; root-mean-square error of approximation $($ RMSEA $)=0.073)$. All in all, it seems that the scales used for this analysis are valid and reliable.

As reported in Table 2, online consumers' perceived CM was significantly correlated with site value $(r=0.34, p<0.00)$, user satisfaction $(r=0.29, p<0.00)$, and online purchase $(r=0.30, p<0.00)$. To further explore the relationship between CM and other variables a multivariate analysis of variance (MANOVA) was used. Two groups (ie, higher level versus lower level of CM) were created by a median split. The independent variable was the CM 
Table 3: Results of CM groups difference

\begin{tabular}{|c|c|c|c|c|c|c|}
\hline Variables & $\begin{array}{l}\text { CM } \\
\text { groups }^{a}\end{array}$ & $\mathbf{N}$ & Mean & SD & $\begin{array}{l}\text { Test Dif } \\
\text { group } 1 \\
t \text {-value }\end{array}$ & $\begin{array}{l}\text { nce }^{b} \text { of } \\
2 \\
\text { Sig. }\end{array}$ \\
\hline \multirow[t]{3}{*}{ Site value } & 1 & 88 & 5.23 & 1.65 & & \\
\hline & 2 & 92 & 5.98 & 1.09 & 3.62 & 0.00 \\
\hline & All & 180 & 5.61 & 1.44 & & \\
\hline \multirow[t]{3}{*}{ User satisfaction } & 1 & 88 & 4.95 & 1.25 & & \\
\hline & 2 & 92 & 5.38 & 0.88 & 2.02 & 0.04 \\
\hline & All & 180 & 5.24 & 1.08 & & \\
\hline \multirow[t]{3}{*}{ Online purchase } & 1 & 88 & 2.89 & 4.18 & & \\
\hline & 2 & 92 & 3.46 & 4.42 & 2.94 & 0.00 \\
\hline & All & 180 & 3.33 & 4.29 & & \\
\hline Providing incomplete & 1 & 88 & 3.65 & 1.77 & & \\
\hline \multirow{2}{*}{ information online } & 2 & 92 & 4.03 & 1.81 & 1.43 & ns \\
\hline & All & 180 & 3.84 & 1.79 & & \\
\hline Providing incorrect & 1 & 88 & 3.88 & 1.93 & & \\
\hline \multirow{2}{*}{ information online } & 2 & 92 & 4.13 & 1.77 & 0.89 & ns \\
\hline & All & 180 & 4.00 & 1.85 & & \\
\hline
\end{tabular}

$\mathrm{a}=$ lower level of $\mathrm{CM} ; 2=$ higher level of $\mathrm{CM}$; ns = not significant.

${ }^{b}$ Results of MANOVA test for the difference between group 1 and 2 are the following: Wilks' Lambda $=0.92$ $(p<0.01)$; Hotelling's Trace $=0.09(p<0.01)$; Pillai's Trace $=0.08(p<0.01)$; Roy's Largest Root $=0.09$ $(p<0.01)$.

group, while the dependent variables included site value, user satisfaction, online purchase, providing incomplete information online and providing incorrect information online. Given the significant correlations among these dependent variables, the MANOVA test was deemed more appropriate than a univariate analysis of variance or simple $t$-test. ${ }^{6}$ In addition, the result of Barlett's test of sphericity $(p<0.0001$ with 15 degrees of freedom) indicated that MANOVA was suitable for testing the hypotheses.

\section{Hypotheses testing results}

The previous hypotheses stated that a higher level of CM leads to a higher level of perceived site value $\left(\mathrm{H}_{1}\right)$, perceived user satisfaction $\left(\mathrm{H}_{2}\right)$ and online purchase $\left(\mathrm{H}_{3}\right)$. In addition, a higher level of CM is posited to lead to a higher level of online CCB of providing incomplete information $\left(\mathrm{H}_{4}\right)$ and providing incorrect information $\left(\mathrm{H}_{5}\right)$. MANOVA results, as reported in Table 3 , indicated that the higher level of CM was significantly different from the lower level of CM (eg, Wilks' Lambda $=0.92$, $p<0.01 ;$ Hotelling's Trace $=0.09$, $p<0.01)$. In particular, internet storefront sites with a higher level of CM tended to deliver more perceived value to online users $(t=3.62, p<0.01)$, supporting $\mathrm{H}_{1}$. In addition, they led to a higher level of user satisfaction with the online experience $(t=2.02, p<0.05)$, supporting $\mathrm{H}_{2}$, and result in more online purchases $(t=2.94, p<0.01)$, supporting $\mathrm{H}_{3}$. However, CM seems unrelated to the online $\mathrm{CCB}$ of providing incomplete information or providing incorrect information, as the associated $t$-statistics $(t=1.43$ and 0.89 , respectively) are not significant. Overall, the results show evidence supporting the key hypotheses $\left(\mathrm{H}_{1}, \mathrm{H}_{2}\right.$ and $\left.\mathrm{H}_{3}\right)$ of the positive side of $\mathrm{CM}$ strategy, but not supporting $\mathrm{H}_{4}$ and $\mathrm{H}_{5}$ of the negative side of $\mathrm{CM}$ in the current study. That is, online users in general perceived that more CM-based internet retailing sites can create more value and generate a more satisfactory online experience for them, and thus they tend to purchase more often via 
these sites. In addition, CM does not result in more online $\mathrm{CCB}$ (eg, providing incomplete or incorrect information online). One possible explanation for this finding may be the fact that, from an economic perspective, online consumers may not choose to complain when the perceived benefits (eg, usefulness and value) are greater than the costs (eg, personal privacy and information search time and efforts).

Overall, these findings, for the first time in the literature, lend some initial empirical evidence to the normative theory of CM. Interestingly, the results of this study support the positive impact of CM, but fail to support the hypothesised negative impact. However, one must acknowledge that, in the extreme, CM might bring up the futuristic vision of marketing illustrated in the film 'Minority Report'. It is easy for CM practices to cross the line into intrusiveness.

\section{DISCUSSION AND FUTURE RESEARCH}

The internet is becoming ubiquitous. Consumers may access the web and internet anywhere and at anytime via wireless devices. The strategy of CM, or providing customised and contextual information to customers at the point of need in real time, becomes the key to reaching and retaining online customers. This study attempted to empirically explore the new business model of CM and its resulting e-commerce performance in a business-to-consumer setting. Survey data of online users were utilised to examine quantitatively the perceived importance of CM and both its positive and negative outcomes. The results provide some initial evidence of the positive influence on users' perceived e-commerce outcomes (eg, site value, user satisfaction and online purchases). In addition, support for potential negative outcomes (eg, CCB of providing incomplete information and incorrect information online) was not found.

The present study contributes to the literature in several ways. First, to the author's knowledge, it is the first empirical study, although exploratory in nature, to comprehensively investigate the CM strategy of internet retailing sites and the potential performance implications for e-commerce from an online user perspective. Secondly, theorises and tests not only the bright side of CM but the dark side as well. It found that CM tends to increase online consumers' perception of site value, satisfaction and repeated purchase, but, importantly and interestingly, does not increase the chance of providing incomplete information or incorrect information online. Thirdly, it contributes to the literature by proposing multiple metrics of e-commerce performance. Most existing metrics are only positive about e-commerce (e-loyalty, e-satisfaction, etc), ignoring the fact that technology is a double-edged sword. It may result in unwanted, unsolicited consequences such as privacy concerns and CCB. Nevertheless, clear and precise metrics are essential for evaluating internet commercial activities. It is the author's hope that researchers may expand the proposed multidimension metrics for theory building and testing and marketers may utilise them as a starting point to benchmark and improve organisational processes.

\section{Implications}

These findings are critical from a managerial perspective because few direct marketing practitioners are capitalising on the surge of wireless web users and the power of CM strategy. Internet storefronts may enhance their 
performance and customer relationships by adopting the concept of CM. New technologies (wireless web, PDAs, interactive television, etc) create ample e-opportunities to effectively target customers in real time. For example, softlock.com introduced dynamic content locking (DCL) technology that enables e-businesses to offer, sell and distribute digital customised products/services in real time to internet users. This DCL technology, by the aid of artificial intelligence, neural networks and wireless connections, can provide potential online shoppers with up-to-the-minute, relevant products at competitive prices. Managers should note that the tools of CM may include wireless telephones, PDAs, interactive web-connected kiosks, electronic wallets and many other access technologies. Mobile devices and internet access will let contextual marketers link real-life situations to virtual service and product offerings. Moreover, CM-based marketers should strive to constantly understand their customers, following the entrepreneurial imperative: do not bring customers to a site, bring the message to them at the point of need in real time instead. In the end, it is contended that a research stream of CM may be fruitful and productive in explaining the future success of electronic commerce.

\section{References}

1 Breitstein, J. (2002) 'Ads in real time', Pharmacentical Executive, Vol. 22, No. 5, p. 124.

2 Kenny, D. and Marshall, J. (2000) 'Contextual marketing: The real business in the Internet', Harvard Business Review, Vol. 78, No. 5, pp. 119-125.

3 Rayport, J. and Sviokla, J. (1996) 'Managing in the marketspace', Harvard Business Review, Vol. 74, No. 6, pp. 141-150.

4 Tobias, H. (2002) 'Using e-business to gain advantage', Journal of Database Marketing, Vol. 9, No. 2, pp. 132-136.

5 Sheehan, K. B. and Hoy, M. (1999) 'Flaming, complaining, abstaining: How online users respond to privacy concerns', Journal of Advertising, Vol. 18, No. 3, pp. 37-51.

6 Hair, J. F., Anderson, R., Tathamm, R. L. and Grablowsky, B. J. (1998) Multivariate Data Analysis, Tulsa, OK; Petroleum Publishing Company. 